required in any individual case. Two circular frames each $2 \frac{1}{2}$ inches in diameter, and with teeth cut in their edges, are mounted, so that the teeth gear into each other, and they can rotate freely, but in opposite directions. In the centre of each frame is mounted a prism of $18^{\circ}$; one of the frames is graduated, and when the graduation is at $0^{\circ}$ the axes of the prisms are parallel, so that parallel pencils of rays falling on both are deviated both in the same direction, and still parallel. Thus when the pair of prisms are arranged horizontally in front of a pair of eyes, an object looked at appears displaced up or down, but there is no lateral deviation on either. If the frames be rotated $90^{\circ}$ in one direction, the prisms both have their bases inwards, or, if in the other direction, both outwards, so that two pencils of rays are deviated to the full power of the prisms. In the in termediate positions part of the prismatic effect is resolved in a direction at right angles to the line joining the centres of the frames, and can be neglected as only producing parallel displacement of the image, and part is resolved in the direction of this line so as to produce apparent separation or approximation of the images. This amount is read off from the graduation, which is constructed on the following principle:-Suppose a ray of light X A O perpendicular to the plane of the paper meets the paper at $O$. Suppose a prism be introduced at $A$

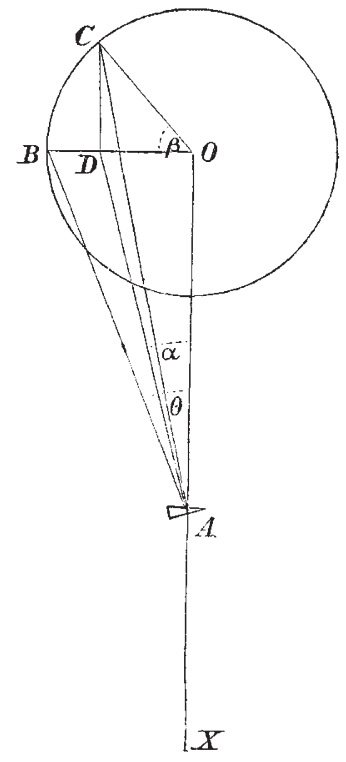

having an angle of deflection $\theta$, the ray of light now falls on the paper at $B$. If the prism be rotated through angle $\beta$, the ray now falls on the paper at $C$. Join $O B, O C$, and resolve $\mathrm{O} C$ into vertical and horizontal co-ordinates $C D, O D$. C D being neglected as described, we wi-h to find OD the horizontal component of the deflection.

$$
\begin{aligned}
\text { Since } O B & =O C \\
\therefore \frac{O D}{O B} & =\frac{O D}{O C} \\
\therefore \frac{O D}{O A} & =\frac{O D}{O C} \\
\frac{\mathrm{OA}}{\tan \alpha} & =\cos \beta \\
\tan \theta & =\operatorname{cog} \tan \alpha-\log \tan \theta .
\end{aligned}
$$

Two other frames are placed in front of the prisms. They contain grooves to hold lenses or combinations of lenses, and are graduated so that cylindrical lenses can be set at any desired angle. The frames can be separated or brought nearer with greater accuracy by a wedge, and the distance of the centres of the glasses is marked on the bearing. The whole is carried at the end of a graduated bar which carries a sliding support for an object. This bar is graduated in inches for use in calculation and also in focal lengths of a set of dioptric lenses. A third prism is attached, so that it can be placed between one of the frames and the object. When it is in position, the rays going through it to the eye appear to come from an object higher than when it is absent. Double vision is produced, and the eyes left free to find their most comfortable position free from any effort to make the two images coalesce. To use the instrument, the spherical and cylindrical elements of the spectacle required are first found either by some of the ordinary methods or by the ophthalmometer described in the Annual Volume for 1880 , and the required lenses from the trial case put in the appropriate frames. The third prism is interposed, and an object, such as a vertical line, looked at at reading distance. If the images seen by the two eyes are exactly one above the other, the prismatic adjustment is presumably correct, the third prism is removed, and trial is made whether reading can be carried on for some time without fatigue. If the images are slightly displaced externally, trial is made whether shifting the centres of the lenses nearer or further off suffices to bring them into position. If so, the distance is noted and sent as a direction to the optician. If the displacement be more than can be corrected by this means, the prisms are rotated till the desired effect is produced, and the amount of prismatic deviation to be given to the proposed spestacles read off. The third prism is removed. and reading practised as above.

\section{SCIENCE AND INDUSTRY ${ }^{1}$}

CONSIDERING the high position in literature and science of my predecessors in this chair, I feel that I have been bold indeed in accepting the distinguished office of President of the Midland Institute during the current year. I shall not attempt to rival my predecessors in those literary or philosophic flights which befitted their powers, but shall confine myself to certain suggestive remarks flowing from personal experience of men and matter, which may prove of some interest to an audience consisting in the main of persons who, like myself, are intent upon combining science with practical aims, but who, unlike myself, have the best part of their career still before them.

In venturing to express my views regarding the great question of the day, that of Technical Education, I shall run considerable risk of disappointing some of its most ardent advocates, who may have looked upon me, a foreigner by birth, as a staunch supporter, if not as the living embodiment, of that particular form of education that the Polytechnicum of Germany and other Continental countries imparts to the aspiring engineer and manufacturer, but which, in my opinion, leaves much to be desired, and is certainly inapplicable to the condition of things which we find in this country.

The subject of education, and of science education in particular, is one the practical and national importance of which it would be difficult to over-estimate. It is well known that the Continental nations have in some respects stolen a march upon us in providing for the education of the young engineer, the architect, the manufacturer, and the craftsman. Colleges of high and low degree abound where buth science and practical processes are taught, whereas the teaching of the latter has been looked on hitherto amongst us as professional or trade knowledge to be acquired during lengthy periods of pupillage or apprenticeship.

The more ardent advocates of the Continental method of technical education go so far as to think that the irksome system of apprenticeship should give way entirely to technical teaching within the college walls, whereby it is assumed much time could be saved and a better knowledge be imparted to the aspiring engineer or manufacturer. Having had some experience of young men brought up at these technical schools, I am bound to say that I have not been favourably impressed with the results produced by that system. The practical knowledge acquired at those establishments is wanting in what may be called the commercial element, that is of due regard to cost of production, of which the teacher himself must be comparatively ignorant, as otlerwise we should find him employed at the factory or engineering office, instead of in the schoolroom.

The young polytechnic student is apt to look on the machine or process which he has studied, not as one of many solutions of a practical problem influenced by ever-varying external circum stances, but as something representing an absolute condition of things almost as completely proved and established as a first

I Abstract of Address at the opening of the Birmingham Midland Institute, by Dr. C. W. Siemens, F.R.S., president of the Institute. 
principle in nature, or a proposition of Euclid; he is very proud of this positive knowledge, and impatient of any suggestion aiming at the accomplishment of the same object by means not sanctioned by his authoritative text-book. He is apt to be a dogmatist, a splendid man for coming out first-class in a competitive examination, and likely enough to make a good official in a Government administration, but most unlikely to venture of himself on such new embodiments of first principles of nature as are essential to the accomplishment of improved result", and as have animated our Watts, our Cromptons, our Corts, and our Bessemers in enriching the world with new processes.

On the Continent, where the Governments themselves are largely engaged in trade and enterprise, where railways, mines, and factories are State establishments, it was necessary to create a large staff of men educated to the point of being able to assume at once a position of some authority in the ranks of rigid organisation, and such men are provided by the polytechnic schools. Our Indian Government being similarly situated, had to resort to similar means, and to establish Cooper's Hill Engineering College.

In this country, where happily the great commercial interests, with one exception, are still in private hands, educational establishments on the Continental model would be, I consider, inappropriate. The object a young man has in view is not the attainment of a snug position in a Government establishment, but to be fitted by his education for the great battle of life, in which he will be judged, nat by the answers he can give to certain set questions in his competitive examination, but rather by the faculty he may have acquired of realising useful results under even adverse circumstances and conditions.

The time was, not long ago, when the opinion prevailed in this country that useful knowledge could only be attained in the workshop; that a lad, after having mastered the three R's at a primary school, had to be bound to a manufacturer or craftsman for a period of seven years, where his time was occupied in routine work or in mechanical repetitions of one and the same operation, causing him to give up thinking altogether, and to become what was dignified by the appellation of practical man - a man of notions, with a supreme contempt of theory or science. The reign of this practical man par excellence is happily drawing to a close; for those who wish to treasure up his memory, I would recommend a lucid description of him by my friend Sir Frederick Bramwell in his presidential address to the Mechanical Section of the British Association in 1872 (which may be found in the Transactions of that year). Since then Sir Frederick Bramwell has done much to hasten the burial of the character he describer, in making himself the principal promoter of that splendid endowment, the London City Guilds Institute, which, under wise direction, cannot fail to exercise a very important influence on the educational development of the country.

Having now spoken, somewhat disparagingly, I fear, of both the old English system and of the more recent Continental system of technical education, I shall be asked, no dcubt, what in my opinion should be the plan adopted in preparing the mechanical engineer, the manufacturer, and the artisan of the future for their respective careers. The answer to such a que ition is one involved in much diffculty, scarcely admiting of universal solution. There are, however, certain principles of general application which, I submit, should never belost sight of Moral education being provided for, the main object in teaching the young should be to strengthen the power of memory, and after that the reasoning faculty. The first is most appropriately accomplished by the conventional three R's, and by the teaching of geography, history, and languages, both ancient and modern; and the second by mathematics, logic, and the natural sciences. Sir John Lubbock, in addressing you some years ago from this chair, forcibly called attention to the necessity of com. bining both literary and scientific education in our grammar schools, suggesting that at least ten hours a week should be given up to the teaching of science.

Such a system of education has since been established at Eton, where (as reported in NATURE, vol, xxiv. p. 287) all pupils attend science classes, and are said to be very fond of what they are pleased to call the "stinks" (in allusion to the chemical laboratory); whereas at other grammar schools a "modern department" has been added to the establishment, where science is taught to those only who elect not to go in for a classical career, whilst the classical scholars remain untaught in science as before I am of opinion that the Eton system is the better of the two, for I cannot regard an education to be complete that does not combine literary with scientific training; the one gives the polish and the other the fibre and practical direction to the understanding. A Birmingham manufacturer by no means despises polish to make his goods tempting in the market, but he would hardly like to offer them composed entirely of lacquer and polish without that solid fibre in the interior that is necessary to fit them for practical usage; such internal fibre may in our case be likened to the knowledge of useful information such as modern languages and natural science, without which the classical polish must be devoid of the power to produce results, which after all is the standard to be aimed at.

The man of classics, the Bishop, the Legislator, and the Judge of the future, educated at Eton, will be none the worse for standing upon an educational foundation comprising "stinks" in its composition, whereas the man of practical pursuits will be all the better for his early literary culture.

But it may be urged that the time available for study is too short to admit of botb, and that one or other must therefore be chosen. I should venture to doubt the sufficiency of this objection, being of opinion that the study of the one kind of knowledge qualifies the mind the better for the other, in the same way as in after life recreative exercise of mind and body is resorted to in order to relieve the drudgery of daily duty.

The usefulness of science teaching depends of course to a great extent upon the teacher, and upon the system adopted. Science taught as it were by rote is of comparatively little value in after life; to be beneficial it should be practical, impressing the mind vividly with the simplicity and the beauty of the laws of nature, and for this purpose each statement of a law shonld be followed up by ocular demonstration, nay by active co-operation on the part of the student in the experiment. For this purpose no school ought to be without its chemical, its physical, and its mechanical laboratories, where students could test for themselves chemical reactions, verify physical laws, and ascertain the mechanical properties of materials used in construction. Nor do these laboratories necessarily involve a large expenditure for apparatus, the most instructive apparatus being that which is built up in the simplest possible manner by means of pulleys, cords, wires, and glass tubes, and, if possible, by calling into requisition the constructive ingenuity of the student himself.

Only after the student has attained a thorough knowledge of first principles will it be desirable to introduce him to elaborate instruments such as teleccopes, polariscopes, electrometers, and delicate weighing-machines wherewith to attain numerical results and to commence original research. For this reason very complete laboratories are of great importance at the universities and superior colleges, where exact science and independent research take the place of mere tuition of first principles.

After first principles have been taught at school, the university on the one hand, and the workshop, aided by study on the other hand, are requisite to impart that special knowledge necessary for the profession c $r$ business to be followed in after-life. In this respect the Gerran University-that glorious institution for the development of independent thought -offers advantages much more commendable for imitation than the technical school, and it is a significant fact that while the thirty universities of Germany continue to increase both as regards number of students and high state of efficiency, the purely technical colleges, almost without exception, have during the last ten years been steadily receding; whereas the provincial "Gewerbe Schule" has, under the progressive Minister, Von Falk, been modified so as to approximate its curriculum to that of the "Gymnasium" or grammar-school.

In some technical schools mechanical workshops are provided, in which students may work at the lathe, the vice, and $t e$ planing-machine, and where they are allowed to construct small steam-engines or other pieces of machinery. I doubt very much whether these toy steam-engines are such as would satisfy a mechanical engineer in real practice, and think that both the money of the institutiun and the time of the student could be much better employed if, instead of imitating practic.l engineering, he were made to experiment with testing-machines in order to obtain a thorouy h insight into the mechanical nature of materials, their absolute strength, their elastic limits, and the effects produced upon them by the processes of annealing, tempering, and welding. University College, London, has taken a lead in this respect under the able direction of Prof. Kennedy, and its example will, I hope, be followed by other colleges.

As regards middle class elucation, it must be borne in mind 
that, at the age of sixteen, the lad is expected to enter upon practical life, and it has been held that under these circumstances at any rate it is best to confine the teaching to as many subjects only as can be followed up to a point of efficiency and have reference to future application. It is thus that the distinc tion between the German Gymnasium or Grammar School and the Real Schule or Technical School has arisen, a distinction which, though sanctioned to some extent in this country also by the institution of the "modern side," I should much like to see abolished.

But I shali be told that it is impossible to teach everything properly within the time, and shall be remin ted of the proverb that says, "A little knowledge is a dangerous thing." I, for one, do not believe in this proverb, which 1 consider erroneous, and mischievous in its application. Referring to myself as an example, I am sorry to state that I had not the advantage of being taught Greek at school beyond the mere letters of the alphabet-my eariy education having indeed been irregular and cut short much too soon-which surely is the minimum of knowledge that could possibly be possessed of that language. Yet even this amount of knowledge of Greek has stood me in good stead, because it has enabled me at any rate to use those letters in mathematical formulæ, and on a push to puzzle out some of those Greek names which are given to scientific instruments. In this case, at least, exceedingly little knowledge has proved no danger, but a considerable advantage to $\mathrm{me}$, and it would not be difficult to multiply example; to the same effect. A little knowled se of a modern language will be best appreciated by an English person who, speaking no languige but his own, has occasion to go abroad. Arriving at his destination he finds that he is unable to make the railway porter understand what conveyance he intends to take, and where he intends to go; his perplexity will be still greater when, on entering a restaurant, say at Paris, he is presented with a bill of fare extenaing over several pages, from which to select his dinner. In despair he points at random to some of the enu neration of dishes, and finds to his discomfiture that the one is presented to him in the form of a paté of snails, another as a preparation of legs of frogs, and the third as water ice with which to appease an app tite quite equal to roast beef, potatoes, and cheese.

In physical science a little knowledge may be a matter of the greatest importance to an artisan when he is called upon to set a machine to work, and is stoppe 1 by some such accidental cause as the accumulation of air below a valve, or unequal expansion due to a local source of heat. The knowledge of a few fundamental laws of physical science will at once enable him to divine the cause of difficuliy, which has only to be recognised in order to be removed. I should therefore be disposed to reverse the proverb, and to say that "a little knowledge is an excellent thing," only it must be understood that this little is fundamental knowledge; that it is not the knowledge of the conceited pretender who has committed to memory a few scraps of information of a particular subject ; who quotes a Greek author without having learned as much of the language as I have; who speaks of planetary perturbations without having a knowledge of the fundamental law of gravitation; or who pretends to know all about steam-engines without having the least knowledge of the laws of heat, of elasticity, or of dynamics involved in their action.

On the whole $\mathrm{I}$ am inclined to agree with Lord Brougham, who, himself a great lawyer and a lover of science, gave origin to the pithy expression, "Try to know something about everything, and everything about something." It would be hard, indeed, to realise the latter portion of his saying, but it would be difficult to know even a good deal about something without knowing at least something about a great many other things.

The question of education bec smes even more difficult when we approach the condition of the artisan who needs to send his boy into the mine or factory at the tender age of twelve years. I am of opinion that fourteen years should be the minimum age at which lads should be admitted into works, in order that they may have had not less than four years of judicious training at elementary or Board schools, where in addition to the purely elementary subjects, at least so much of general history, easy mathematics, and natural science should be inculcated as to implant, if possible, the desire to acquire more of those subjects in after life. School education, whether followed up to one poin or another, can after all do no more than lay a foundation and implant, if possible, a desire in the mind of the student to follow up the subjects taught in maturer years with the experience of life present to give a practical direction to his studies.

In order to aid him in these endeavours, such bodies as the Mid. land Institute must prove to be of great service, with its science classes and lectures open to all who thirst after knowledge and who want to understand more particularly the scientific principles involved in their occupations. 'Technical education such as this is indeed indispensable if this country is to maintain the supremacy won for it by men of exceptional genius, enterprise, and perseverance, but which without it can hardly be expected to withstand in the long run the competition of foreign nations, with cheaper labour and a higher standard of general education in their favour. The English system of technical education has this advantage over the system established elsewhere, that it is not governmental but essentially spontaneous and self-supporting, and will therefore shape itself into the mould best suited to the free and vigorous development of trade itself.

The system of pupillage or apprenticeship will still be necessary, but instead of involving the sacrifice of seven of the most important years of a young man's life, half that time, or say three years, will be found amply sufficient to give to the lad imbued with first principles the practical knowledge necessary for his trade. The employer would be amply compensated for the shorter time of gratuitous service by a corresponding improvement in its quality. He should be expected to see to it that during the term of his authority the pupil attended Saturday and evening classes, where, in addition to general subjects, the principles underlying the operations of his business of spinning, dyeing, paper-making, or metal-working are taught by competent persons.

It is important that the teacher himself should not be a mere specialist, but a man capable of generalising and of calling to his aid other branches of science and general knowledge, that he should be, in short, a well-educated person. It is difficult, I believe, as yet to find a sufficient number of teachers equal to such a standard, and in order to supply this deficiency normal schools will have to be established upon a much larger scale than has hitherto been the case. It is satisfactory to learn that South Kensington is coming to the rescue in converting its science teaching into a normal school for the education of science teachers; only it is to be hoped that literary subjects will be added to their curriculum.

The importance of a higher education of the working classes will be appreciated by all who have watched the rapid strides with which one branch of industry after another undergoes fundamental change, by which the mere craft-skill acquired yesterday becomes obsole:e to-day, when a new process, involving entirely new modes of operation, takes the place of a previous one. Nor is there any promise of stability in the process of to-day, which may be again superseded to-morrow by something more nearly approaching ultimate perfection.

To those who still have some confidence in the stability of things as they exist in arts and manufactures, I would strongly recommend a trip to Paris, where they will still be in time to visit the International Exhibition of Electricity. That form of energy known as the electric current was nothing more than the philosopher's delight forty years ago. Its first practical application may be traced to this good town of Birmingham, where $\mathrm{Mr}$. George Elkington, utilising the discoveries of Davy, Faraday, and Jacobi, had established a practical process of electroplating in 1842 .

It affords me great satisfaction to be able to state that I had something to do with that first practical application of electricity; for in March of the following year, I843, I presented myself before Mr. Elkington with an improvement on his processes, which he adopted, and in so doing gave me my first start in practical life. Considering the moral lesson involved, it may interest you, perhaps, if I divert for a few minutes from my subject in order to relate a personal incident connected with this my first appearance arnongst you.

When the electrotype process first became known, it excited a very general interest, and although I wa; only a young student of Göttingen under twenty years of age, who had just entered upon his practical career with a mechanical engineer, I joined my brother Werner Siemens, then a young lieutenant of artillery in the Prussian service, in his endeavours to accomplish electrogilding, the frrst impulse in this direction having been given by Prof. C. Himly, then of Göttingen. After attaining some promising results, a spirit of enterprise came over me so strong that $I$ tone myself away from the narrow circumstances surrounding me, and landed at the East End of London with orly 
a few pounds in my pocket and without friends, but with an ardent confidence of ultimate success within my breast.

I expected to find some office in which inventions were examined into, and rewarded if found meritorious, but no one could direct me to such a place. In walking along Finsbury Pavement I saw written up in large letters "So and so" forget the name), "Undertaker," and the thought struck me that this must be the place I was in quest of ; at any rate, I thought that a person advertising himself as an "undertaker" would not refuse to look into my invention with a view of obtaining for me the sought-for recognition or reward. On entering the place I soon convinced myself, however, that I came decidedly too soon for the kind of enterprise here contemplated, and finding myself confronted with the proprietor of the establishment, I covered my retreat by what he must have thought a very lame excuse. By dint of perseverance I found my way to the patent office of Messrs. Poole and Carpmael, who received me kindly and provided me with a letter of introduction to $\mathrm{Mr}$. Elkington. Armed with this letter, I proceeded to Birmingham to plead my cause before your townsman.

In thinking back to that time, I wonder at the patience with which Mr. Elkington listened to what I had to say, being very young, and scarcely able to find English words to convey my meaning. After showing me what he was doing already in the way of electro-plating, Mr. Elkington sent me back to London in order to read some patents of his own, asking me to return if, after perusal, I still thought I could teach him any. thing. To my great disappointment I found that the chemical solutions I had been using were actually mentioned in one of his patents, although in a manner thai would hardly have sufficed to enable a third person to obtain practical results.

On my return to Birmingham I frankly stated what I had found, and with this frankness I evidently gained the favour of another townsman of yours, Mr. Josiah Mason, who had just joined Mr. Elkington in business, and whose name as Sir Josiah Mason will ever be remembered for his munificent endowment of education. It was agreed that I should not be judged by the novelty of my invention, but by the results which I promised, namely, of being able to deposit with a smooth surface $3 \mathrm{dwt}$. of silver upon a dish-cover, the crystalline structure of the deposit having theretofore been a source of difficulty. In this I succeeded, and I was able to return to my native country and my mechanical engineer. ing a comparative Crcesus.

But I was not to remain there, for in the following year I again landed in the Thames with another invention, worked out also with my brother, the Chronometric Governor, which, though less successful, commercially speaking, than the first, obtained for me the advantage of bringing me into contact with the engineering world, and of fixing me permanently in this country. This invention was in course of time applied by Sir George Airy, the then Astronomer-Royal, for regulating the motion of his great transit and touch recording instrument at the Royal Observatory, where it still continues to be employed. Another early subject of mine, the anastatic printing process, found favour with Faraday, "the great and the good," who made it the subject of a Friday evening lecture at the Royal Institution. These two circumstances combined obtained for me an entry into scientific circles, and helped to sustain me in difficulty until, by dint of a certain determination to win, I was able to advance step by step up to this place of honour situated within a gunshot of the scene of my earliest success in life, but separated from it by the time of a generation. But notwith. standing the lapse of time, my heart still beats quick each time I come back to the scene of this, the determining incident of my life.

At the time I am speaking of, the electric telegraph was occupying the minds of the philosophers of different countries, but it was not until the year 1846 that the first practical line of telegraph was established between Paddington and Slough, where it soon gained notoriety in preventing the escape from justice of a great criminal. It is unnecessary for me to insist upon the enormous results that have been achieved by this great modern innovation, which goes even beyond the poetic vision of Shakespeare himself, who in the extravagance of his "Midsummer Night's Dream " makes Puck " encircle the earth in forty minutes," a rate of communication which would nowadays hardly satisfy the City merchants, who expect Calcutta and New York to respond to their calls much more promptly than that.

The telegraph has found its simplest but most remarkable development in the telephone, which, although shadowed forth

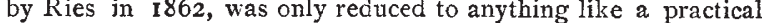
shape by Graham Bell in 1876 , and subsequently extended by Edison, Hughes, and others.

This latter invention appeared at first particularly unpromising of practical results. The currents set up through the vibrations of a metallic diaphragm facing the poles of a small magnet are so feeble, and the rate of succession of currents necessary to produce sound (represented by 440 vibrations per second to produce the note fundamental $l a$ ) was so very much beyond anything met with in telegraphy, that it was difficult to conceive how such a succession of distinct currents with the infinite variety of strength and quality necessary to reproduce speech could be transmitted through a line wire many miles in length, and could reproduce mechanically the same sounds at the receiving end. Yet the telephone has become a practical reality, and its ultimate powers are illustrated in a very remarkable manner at the Paris Exhibition.

There, in a certain room, you may listen of an evening one minute to the performance going on at the Great Ofera House, the next minute to an air sung at the Opéra Comique, and again the next minute to the well-known voices of the principal actors of the Theatre Français. The novelty of this particular arrangement consists in having each receiving telephone connected separately to a transmitting telephone, fixed in front of the footlights towards the two sides of the stage, whereby an acoustic effect is produced that may almost be called stereoscopic; you actually hear when the actor turns his or her head from one side to the other, and are able to separate most distinctly the several voices, as well as the orchestral instruments when concerted music is being produced. Nor are the sounds in any way distorted cr disagreeable, or too low to be enjoyable, but loud and full, producing an agreeable impression even on the musical ear. The person with his ears to the two receiving telephones imagines himself in a mysterious dreamland of sound, but remove the instruments only half an inch from the ear, and all has departed; no sweet sounds of music are heard, but in their stead the speaking voice of the person anxious to take your place at the auditory. I leave to your imagination to picture the innumerable applications which this new power of man in directing the forces of nature may ultimately lead to.

The most striking feature upon entering the Paris Exhibition in the evening is the blaze of electric light that makes the interior of that large building even brighter than by daylight; nor is the effect of this illumination marred by the flickering, fizzing, and colour changing of the earlier attempts in this direction. The character of the lights comprises a range from the central arc of Io, ooo candle-power, to the incandescent lamp of only fifteen candles, equalling the light only of an ordinary gas-burner, and the grouping and shading of some of these lights are such as to produce effects extremely agreeable to the eye. Who would venture to say, after this display, and after the practical applications that have been made of the electric light in the City of London, at several of our docks and harbours, at works, halls, and theatres, that it is not a practical illuminant destined to work as great a change as gas-lighting did before it,ithirty years ago, when it was inaugurated at the Soho Works not many miles away from this hall?

But although I predict a great future for electric light as being the most brilliant, the cheapest, and the least objectionable from a sanitary point of view of all illuminants, I do not agree $w$ ith those who consider that the days of gas must therefore be at an end.

In addressing the British Association of Gas Managers in this town a few months ago, I called attention to certain means by which gas of much higher illuminating power might be obtained from the ordinary retorts, if only, at the same time, the gas companies or corporations could be induced to supply at a reduced rate heating gas, of which we so much stand in need; and how, by certain improvements in the burners themselves, the illuminating power of a given quantity of gas might be still further augmented. Gas companies have for many years enjoyed the sweets of their monopoly position, which position is generally speaking not productive of desire for change. The electric light bas furnished for them the incentive to advance, and the effect of that incentive has told already, I am glad to observe, in a very striking manner upon the street illumination of this immediate neighbourhood.

The time is not far distant, I believe, when gaseous fuel will almost entirely take the place of solid fuel for heating, for obtaining motive power, and for the domestic grate; and if gas 
companies and corporations rightly understand their mission, they will take timely steps to supply, separately, heating gas at a greatly reduced cost, the demand for which would soon be tenfold the gas consumption of the present day. The economy and the comfort which would accrue to the inbabitants of large towns by such a change would be great indeed, and it would, amongst other things, effect a radical cure of that great bugbear of our winter existence, a smoky atmosphere.

The third great practical illustration furnished by the Paris Exhibition has reference to the transmission of power from one place to another by means of the electric conductor. When, only five years ago, in addressing the Iron and Steel Institute, I ventured upon the assertion that the time was not distant when the great natural sources of power, such as waterfalls, would be transferred to considerable distances by means of stout electric conductors, to be there utilised for providing towns with light and motive power, I elicited an incredulous smile even from some of those most conversant with the laws of electricity. Electricity had been looked upon by them as a swift agent to flash our thoughts from country to country, but the means of producing that form of energy by the expenditure of power on the dynamo-electric machine, although known, was not yet properly appreciated. Such can hardly now be considered the case. I could point to at least three instances in this country where power is practically transmitted to a distance by means of electricity, to be utilised for pumping water, for lighting, and for working machinery, and the Paris Exhibition furnishes additional illustration of the facility with which that transmission may be effected.

The electric railway leading from the Place de la Concorde into the Exhibition, and only half a kilometre in length, does its work regularly and well, running a trip every five minutes, and conveying generally as many passengers as can be packed both inside and outside of a tram-car of ordinary dimensions. This system of propulsion will soon be in operation on a new line of railway six miles long, with which I am connected, in the north of Ireland, to be extended, if successful, to a further equal distance. This will give us twelve miles of electric railway worked without expenditure of fuel, for the motive power will be obtained from a neighbouring waterfall, which at present runs to waste. Mr. W. A. Traill, the Resident Engineer of the line, has already commenced operations, and I hope that by next spring, visitors to the sister island may reach one of its most interesting sights, the Giant's Causeway, propelled by invisible but yet potential agency.

The experience gained by my brother in the working of the first electric railway, two miles in length, established by him at Lichtenfelde, near Berlin, leaves no reasonable donbt regarding the economy and certainty of this mode of propulsion, although it is not anticipated that it will supersede locomotive power upon our main trunk railways. It will have plenty of scope in re. lieving the toiling horses on our tramways, in use on elevated railways in populous districts, and in such cases as the Metropolitan Railway, where the emission of the products of combustion causes not only the propulsion but the suffocation of passengers.

Another application of electricity, also at any rate indicated at the Paris Exhibition, is that to agriculture and horticulture, upon which $I$ have been practically engaged during the last two winters on my farm near Tunbridge Wells. This is neither the time nor place for me to enlarge upon this application, which should be mentioned, however, because I believe that it will ultimately exercise a considerable influence upon an important interest, besides providing a means of adding to the pleasures of country pursuits. Electroculture by itself would be expensive, but not so if combined, as it is at Sherwood, with the utilisation of electric"energy for accomplishing other objects-such as chaff- and root-cutting at one place, woodcutting at another, and pumping of water at a third, while the waste heat of the steam at the generating station is utilised to heat the water circulating through the greenhouses, \&c. In this way labour and expense are saved in many ways, and the men employed on the farm find no difficulty in working the electrical horses, no longer experimentally, but as a regularly established thing.

A somewhat special application of electricity, also shown at the Paris Exhibition, is its employment as a heating agent. For temperatures not exceeding that of a welding furnace, solid or gaseous fuel produces the desired effect at a cheaper rate than it is likely to be accomplished by electricity. When electricity is used, heat energy has in the first place to be transferred from the burning fuel to the boiler of the steam-engine. The mechanical energy of the engine works the dynamo-electric machine, whence electric energy is transmitted through the conductor to the point where it is to be utilised as heat. At each intermediate stage a loss will have to be incurred, and it is therefore absolutely certain that the amount of heat finally produced in the electric arc must fall very much short of that generated by the fuel under the boiler. But the electric arc has this advantage over other sources of heat, that no waste heat need pass away from it in the shape of heated products of combustion. This loss of heat in the furnace by combustion increases with the temperature at which the work has to be accomplished, and reaches its maximum in a furnace for melting steel or platinum. Beyond this the point is soon reached where combustion ceases entirely, where, to use the scientific phrase, the point of dissociation of carbonic acid is reached; and it is for purposes where such degrees of heat are required that the electric are can be advantageously employed, and will enable us to accomplish chemical effects which have hitherto been beyond the reach of science.

My chief object in dwelling, perhaps unduly, upon these practical questions is to present to your minds in a concrete form the hopelessness of looking upon any of the practical processes of the present day as permanent, to be acquired in youth and to be the staple occupation of a lifetime.

The respectable millwright of former years had already to enlarge his scope of knowledge and become a steam-engine builder ; having made himself master of the construction of simple forms of high-pressure engines, he has had to go to school again, to study the laws of condensation and of the expansive action of steam, in order to produce an engine using only a fractional amount of the fuel which his customers were willing to expend in former years for a given effect; he now has to study the laws of electricity and understand the construction of dynamo-electric machines, in order to be able to transmit and distribute his steam power more readily than could be accomplished by means of wheels and belts. But even his condensing steam-engine with variable expansion, of which he is so justly proud to-day, will no longer be acceptable to his client tomorrow, when it will be made clear to him, by the light of thermo-dynamics, that even the best of steam-engines utilises barely a seventh part of the heat-energy residing in fuel, and that the attainment of perhaps three-fourths of that ultimate limit will be required of him.

Analogous changes threaten to invade almost every existing branch of industry, and it is necessary for every one of you to be prepared for such changes.

The practical man of former days will have to yield bis place to the unbiased worker who with open mind is prepared for every forward step as it arises. For this purpose it is necessary that he should possess, beyond the mere practical knowledge of his trade, a clear appreciation of the principles of action underlying each operation, and such general acquaintance with the laws of chemistry and physical science as will make it easy for him to adapt himself to the new order of things.

In order to be so prepared, it is by no means necessary that you should have had the advantage of an elaborate school education. No man or woman should consider him or herself out of school until approaching the final reckoning, and it is through advantages such as are offered by the Midland Institute, that the means are afforded you of continuing the educational process near your homes, and without much expense or difficulty of any kind.

Let no one of you suppose that his early training or natural ability is unequal to the task of making a career in life. Goethe, that man of wonderful insight into the working of the human mind, says :-

Or, translated, "Was man sich in der Jugend wünscht,$$
\text { Hat man ich in der Jugend wi }
$$

"What you desire in youth,

Mature age will give you in abundance."

At first sight this expression seems to involve almost an absurdity, and it is necessary to interpret the "desire" of youth to mean not simply a vague sentiment or wish to be looked up to in after life, or to drive about in easy carriages, but a determination to leave no stone unturned, and let no opportunity go past that may advance you towards the well-defined object of your ambition. With a firm resolution almost every difficulty in your way will recede before you; disapfointments you will 
have, and they are most desirable, because they are the real teachers in practical life, only you must not allow yourself to be discouraged, but rather to be strengthened by them, in your determination to succeed.

A fond mother has sometimes come to me with a doleful story that her son, "an excellent young man," had tried several things in life and had always failed, through some untoward circumstance, but that she felt sure he would succeed if I would only give him a trial in my own particular pursuits. On some occasions I have perhaps yielded to such representations, but found that the "excellent young man," though commencing with a certain vigour, soon tired of the new occupation when he approached its difficulties. He could not realise the fact that the secret of success lies not in the avoidance of, but in the victory over difficulties, that each disappcintment teaches an important lesson, and that by taking these lessons to heart without swerving from his purpose he would soon find himself possessed of a power exceeding his most san zuine expectations.

Success in life depends in fact much more upon diligence and steadiness of purpose than upon the more brilliant qualities possessed by an individual; but in order to give force and direction to the sterling qualities within him, it is most important that means should be brought within his reach of enriching his stock of useful information. The Birmingham and Midland Institute, counting its 2688 students of various degrees and of both sexes, has accomplished this important object in a manner never before dreamt of ; bit not content with this splendid result, the Council has made provision for a further extension of its beneficial action through the erection of this magnificent lecture hall, which it is my froud privilege to inaugurate this evening, for the use of our members.

\section{UNIVERSITY AND EDUCATIONAL INTELLIGENCE}

CAMBridge.-One interesting outcome of recent changes is the promulgation by the Governing Body of Caius College of the following scheme, to take the place of the regulations providing for the annual delivery of the Thruiton speech on the progress of medicine from the time of Dr. Caius, by a medical graduate, who received the sum of $18 l$. :-The money-about $54 l$ - - shall be given triennially to that member of the College who has published in the curse of the preceding three years the best original investigation in physiology (including physiological chemistry), pathology, or practieal medicine ; the person to whom the prize is aw arded being required to give an account of his investigation in the form of a lecture in the College. If within the specified period no investigation of suffieient merit shall have been made, the money shall be carried forward to augment future prizes; the first prize will be awarded in 1884 .

\section{SOCIETIES AND ACADEMIES}

Entomological Society, October 5.-H. T. Stainton, F.R.S.. president, in the chair. - Exhibitions: Mr. R. McLachlan, a specimen of Gastrophysa raphani, Fabr., bred from a parthenogenetic ovum.- Mr. T. Wood, an abnormal specimen of Notiophilus biguttatus, Fabr.-Mr. R. Meldola, on behalf of Mr. W. J. Argent, some interesting varieties of British Lepidoptera.-Mr. H. B. Pim, a specimen of Harpalus discoideus, Fabr,-Mr. E. A. Fitch, Lasius mixtus, Nyl., an ant new to Britain.-Mr. A. S. Olliff, a specimen of Papilio Americus, Koll., with abnormal neuration.-Communications: the Secretary read a letter respecting the ravages of Lopaphus cocophages, Newp., de tructive to cocoa-nut trees in Fiji ; and some further communications from the Colonial Office relative to locusts in Cyprus, \&c. - Papers read: Mr. D. Sharp, Descriptions of some new Coleoptera from the Hawaiian Islands. Mr. C. O. Waterhouse, on some new South American Coleoptera of the family Rutelida.-Prof. Westwood, description of the immature state of a Ceylonese insect apparently belonging to an undescribed genus.-Mr. P. Cameron, notes on Hymenoptera, with descriptions of new species.

\section{PARTS}

Academy of Sciences, October 10.-M. Wurtz in the chair. -The following papers were read:-On the first volume of the "Nouvelles Annales de l'Observatoire de Bruxelles," by M. Faye. It contains a new uranometry, and a repertory of constants of astronomy. M. Houzeau has represented the Milky Way on a large scale by means of curves of equal luminous intensity. He distinguishes thirty-three luminous masses, care- fully determining their position. Our solar world is situated almost exactly in the plane of the great celestial circle these nearly form, and is probably near its centre. The "Catalogue des Constantes" comprises seventy-six determinations of the solar parallax, extending over twenty-one centuries. The increasing precision of astronomical measurements is well brought out.-M Daubrée presented a large specimen of a holosideric meteorite from Cohahuila, Mexico. It contains chrome-iron, a mineral not before met with in a metallic meteorite. Prof. Laurence Smith also found in it another chromiferous mineral, Dawbréclite. - On the employment of tar as a preservative against phylloxera, by M. Avignon. A mixture is made of tar and fine sand, and triturated to render it homogeneous. Wood-ash is added; the mixture is put in a hole round the stem in spring and covered with earth. It effectually repels the insect.-A letter of M. Govi relating to a brockure by Prince Boncom. pagni on the unpublished will of Nicolo Tartaglia, noted the fact that the true surname of this celebrated mathematician of Bresềi was Fontana. He was called Tartaglia (which means a stammerer, and which appears as his name, even in the will) because of difficult articulation arising from a bad wound in bis jaw and palate received when he was a boy, during the sack of Brescia in 1512.-Comet di covered by Mr. Denning on October 4 I $88 \mathrm{r}$; observation at Marseilles Observatory, by M. Coggia.- - On the part of M. Arnaud, a sample of a new alkaloid from quinquina (of Santander, Columbia) was presented; M. Arnaud calls it cin. chonamine. It differs from cinchonine by an excess of two atoms of hydrogen, and presents the composition of hydrocinchonine, with which it is probably isomeric. - On the sounds produced in a telephonic circuit during thunderstorms, by M. de Lalagade. He recalls effects similar to those got by M. Thury, which he described in 1878 . To amplify the sounds he afterwards added two small microphones to the plate of the receiving telephone; the least sounds can thus be heard $\mathrm{I} \mathrm{m}$. or more from the second telephone in a quiet room. - Galvanometer with angular deflections proportional to the inten-ities, by M. Gaiffe. The multiplier frame in the instrument presented (a horizontal galvanometer) was of elliptic form. The deflections are regular under two angles of about $35^{\circ}$, representing 35 milliwebers, on either side of zero, and then diminish slowly, allowing of division of the scale by units to the fiftieth milliweber. With a different curve of the multiplier frame the deflections may be rendered proportional up to about the seventy-fifth degree.-On the innervation of the heart and the action of poisons in lamellibranchiate mollusca, by M. Yung. Inter alia, the heart is chiefly innervated by fibres from the potterior or the branchial ganglions, which fibres have an accelerative rôle. Rise of temperature accelerates the heart's movements up to $40^{\circ} \mathrm{C}$. Curare, in strong dose, makes the animal's movements very slow. Strychnine, whatever the dose, only causes temporary convulsions, never tetanus; in direct con. tact with the heart it lessens the number of beats, and causes stoppage in fifteen to thirty minutes. Nicotine accelerates the heart-beats, enlarges the heart, and in strong dose causes death. Veratrine acts similarly, \&c.

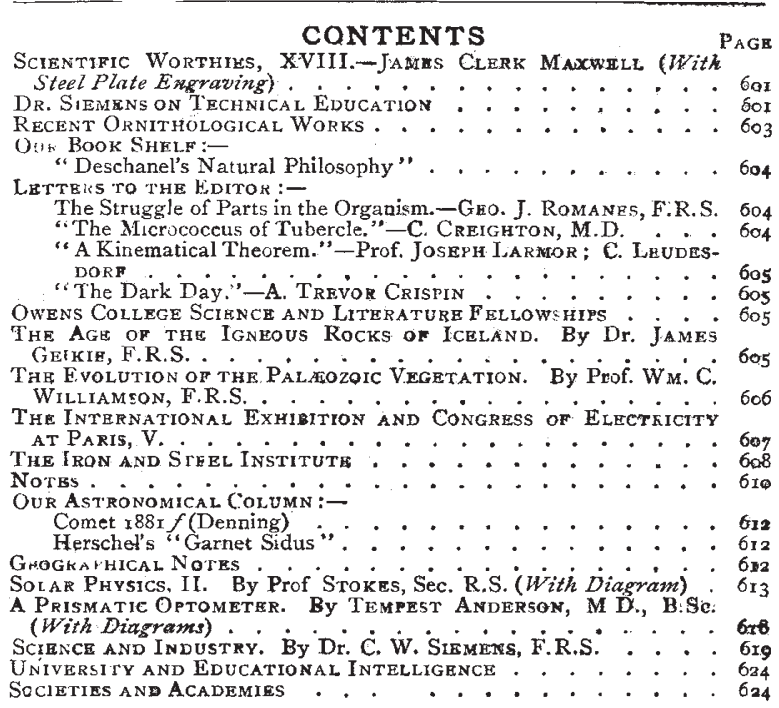

